\title{
Integrated Medicine from the Perspective of Clinicians - How Chinese Doctors Integrate Traditional Medicine and Modern Medicine in Clinical Practice
}

\author{
Xia Wang ${ }^{1}$, Fei Wei ${ }^{2}$ and Muxin Wei $^{3 *}$ \\ ${ }^{1}$ The Second Affiliated Hospital of Nanjing University of Traditional Chinese Medicine, China \\ ${ }^{2}$ School of medicine and life sciences, China \\ ${ }^{3}$ Division of Traditional Chinese Medicine, China
}

Submission: February 10, 2017; Published: February 15, 2017

*Corresponding author: Muxin Wei, Division of Traditional Chinese Medicine, the First Affiliated Hospital with Nanjing Medical University, Associated director of Institute of Integrated Medicine, Nanjing Medical University, Nanjing 210029, Jiangsu Province, China, Tel: +86-2568136267; Email: weimuxin@njmu.edu.cn Tel: +91 832 2222444; Email: weimuxin@njmu.edu.cn

\begin{abstract}
Modern medicine, which is based on direct observations and objective analysis, is defined as experimental science. However, human body itself as a disease carrier is often ignored while identifying pathogenic mechanism at local scale. With the change of the disease spectrum and the rising demand of physical health, it is impossible for modern medicine to fight alone. Integrated medicine, which breaks the boundary of disciplines, strives to apply optimized method to prevent and treat diseases, reflecting the objective of putting people first. It embraces the latest technology and complies with the trend of big data medicine, showing the strength of integrating traditional Chinese medicine and western medicine when new health threat arises and becoming an effective approach to prevent and treat diseases in China.
\end{abstract}

Keywords: Traditional medicine; integrated medicine; clinic; health; Diseases prevention

Abbreviations: PLGC: Precancerous Lesion of Gastric Carcinoma

\section{Introduction}

Medicine is the backbone science preserving human health. However, with the development of the society, modern medicine is put under unprecedented pressure as human health is compromised by hazards from natural environment such as smog and PM2.5 and threatened by unknown pathogenic microorganisms such as SARS as well as varied negative living and dieting habits. Many diseases like precancerous lesion of gastric carcinoma (PLGC) can be accurately diagnosed thanks to modern medical technology, but its treatment falls short of satisfaction [1,2]. In addition, modern medicine lacks experience in improving the physique and regulating health. Clinicians have to treat not only the disease, but also the physique of the patient. Given this background, it is beneficial for the clinicians to understand and command some supplementary and alternative medicine to find more options to help the patients recover and restore health. This paper, from the perspective of a practicing clinician, discusses the dimensions of supplementary and alternative medicine which is called integrated medicine in China.

\section{The Status of Traditional Chinese Medicine}

The medical systems relying on thousand-year-long experience in different countries before the birth of modern medicine can well be defined as traditional medicine. Traditional Chinese medicine, which is widely practiced in China, is in the leading position of traditional medical systems. Besides its widespread application and numerous practitioners, traditional Chinese medicine also boasts a complete theoretical system by drawing on ancient philosophies (Qi, Yin and Yang, Five Elements, etc) and then-current natural sciences such as mathematics, astronomy and geography.

Surprisingly enough, this theoretical system is still effective in guiding clinical practice after 2500 years. What is the status of traditional medicine? In China, traditional Chinese medicine 
is often put on an equal footing with western medicine and integrated medicine in the consideration of preserving the ancient medical system. In reality, however, modern medicine is still in the dominant position. Supplementary and alternative medicine, as traditional medicine is defined in United States, is perhaps more accurate. It is inferred that the dominant modern medicine is often preferred by the patients and doctors when it can readily cure diseases. However, in situations when obstacles and toxic and side effects are inevitable during the treatment of western medicine, traditional medicine may set in as supplementary medicine. While in other situations when diseases such as above-mentioned PLGC, of which modern medicine is incapable to cure and in which traditional medicine is experienced, occur, traditional medicine is required to play a dominant role as an alternative medicine [3].

\section{Modern medicine is not enough to treat all diseases}

Modern medicine is derived from ancient western medicine which, in turn, originates from ancient Greece. Direct observation and objective analysis is essential to modern medicine, which is therefore defined as experimental science. Until today, pathogenic mechanism has been explained from the cellular and molecular perspective and DNA in a bid to guide diagnosis and treatment of diseases. This reflects the human understanding of the world is in constant progress. Nevertheless, objective and direct observation and cautious deduction is always the mindset we adhere to. The fundamental idea of modern medicine is eliminating obscurely defined concepts and empty predictions and illusions to find the truth. Such mindset, however, often ignores the overall influence on the human body as the disease carrier while identifying truth about pathogenic mechanism at local scale. Therefore, with the development of the world, the change of the disease spectrum and rising demand for physical health, it won't do for modern medicine to fight alone, and its limitations are also revealing gradually. For example, how to prevent the severe damage done to normal cells by anti-cancer drugs during cancer treatment? How to help patients recover from extreme fragility after treatment of contagious diseases even though the pathogenic microorganism is eliminated? These questions are difficult to be solved by modern medicine. Therefore, supplementary and alternative medicine is believed to play a larger role not only in China, but also throughout the world.

Integrated Medicine from the Perspective of the Clinicians

Integrated medicine, as an innovative discipline in China, has come into existence for several decades. All disciplines have to assimilate the knowledge created by the mankind to enrich and develop, modern and traditional medicines are no exception. Integrated medicine, which breaks the interdisciplinary boundary, strives to explore the optimized method to prevent and treat diseases and gives priority to the interest of patients, reflecting the objective of putting people first. Practitioners in the field of integrated medicine in China are mostly TCM clinicians who have received modern medical education and a few clinicians who have received advanced western medical education. This new generation of clinicians has introduced traditional medicine into the mainstream medicine and made contribution to the preservation, innovation and promotion of the theoretical system and clinical characteristics of traditional Chinese medicine by integrating it with western medicine. Practicing clinicians not only use the four diagnostic methods of traditional Chinese medicine, but also the modern laboratory and medical instruments used by western medical practitioners to diagnose. These clinicians also have explored chemical language that is consistent with western medicine and made the plantderived new drugs research possible by communicating and expressing the experience and formulas of traditional Chinese medicine and exploring pharmacological efficacy.

With the development of science and technology, integrated medicine assimilates the latest technology and complies with the trend of big data medicine. Integrated medicine also exhibits strength when new health threat arises. Experts in the field of integrated medicine have set out to study the environmentborne pathogenic factors such as smog whose pathogen is yet unidentified. This is where the strength of traditional Chinese medicine lies. Through comparison, analysis, research and application of scientific thinking, theoretical systems, diagnostic and treatment techniques between traditional Chinese medicine and western medicine, integrated medicine have assimilated and integrated the respective characteristics and strengths of both traditional Chinese medicine and modern medicine, accomplished substantial results in disease prevention and treatment and health preservation, and realized the goals of better serving the mankind in areas of health preservation, disease prevention, treatment and recovery. As an effective approach to prevent and treat diseases in China, integrated medicine has exhibited impressive sustainability.

\section{Author Contribution}

$\mathrm{X}$ Wang and F Wei contributed equally to this work.

\section{References}

1. Vannella L, Lahner E, Annibale B (2012) Risk for gastric neoplasias in patients with chronic atrophic gastritis: a critical reappraisal. World Journal of Gastroenterology 18(12): 1279-1285.

2. Zullo A, Hassan C, Repici A (2013) Intestinal metaplasia surveillance: Searching for the road-map. World Journal of Gastroenterology 19(10): $1523-1526$

3. Fan YF, Wei MX (2012) Precancerous lesions of gastric cancer: Research progress and preventive strategies. World Chinese Journal of Digestology (20): 1807-1812. 

(C) Commons Attribution 4.0 Licens

\section{Your next submission with Juniper Publishers} will reach you the below assets

- Quality Editorial service

- Swift Peer Review

- Reprints availability

- E-prints Service

- Manuscript Podcast for convenient understanding

- Global attainment for your research

- Manuscript accessibility in different formats ( Pdf, E-pub, Full Text, Audio)

- Unceasing customer service

Track the below URL for one-step submission https://juniperpublishers.com/online-submission.php 